3-5-2018

\title{
Determinants of medical tourism destination selection process
}

Mohammadali Zolfagharian

Rajasree K. Rajamma

Fairfield University, rrajamma@fairfield.edu

Iman Naderi

Fairfield University, inaderi@fairfield.edu

Samaneh Torkzadeh

Follow this and additional works at: https://digitalcommons.fairfield.edu/business-facultypubs

Copyright 2018 Taylor \& Francis

"This is an Accepted Manuscript of an article published by Taylor \& Francis in Journal of Hospitality Marketing \& Management on 5 March 2018, available online:

http://www.tandfonline.com/10.1080/19368623.2018.1444527."

The author post-print has been archived here with permission from the copyright holder.

\section{Peer Reviewed}

\section{Repository Citation}

Zolfagharian, Mohammadali; Rajamma, Rajasree K.; Naderi, Iman; and Torkzadeh, Samaneh, "Determinants of medical tourism destination selection process" (2018). Business Faculty Publications. 183.

https://digitalcommons.fairfield.edu/business-facultypubs/183

\section{Published Citation}

Zolfagharian, Mohammadali, et al. "Determinants of medical tourism destination selection process." Journal of Hospitality Marketing \& Management, 27, no. 7 (2018): 1-20. doi:10.1080/19368623.2018.1444527.

This item has been accepted for inclusion in DigitalCommons@Fairfield by an authorized administrator of DigitalCommons@Fairfield. It is brought to you by DigitalCommons@Fairfield with permission from the rightsholder(s) and is protected by copyright and/or related rights. You are free to use this item in any way that is permitted by the copyright and related rights legislation that applies to your use. For other uses, you need to obtain permission from the rights-holder(s) directly, unless additional rights are indicated by a Creative Commons license in the record and/or on the work itself. For more information, please contact digitalcommons@fairfield.edu. 


\title{
Determinants of Medical Tourism Destination Selection Process
}

\author{
Mohammadali Zolfagharian, Ph.D. \\ University of Texas Rio Grande Valley, Edinburg, TX, USA \\ Rajasree K Rajamma, Ph.D. \\ Fairfield University, Fairfield, CT, USA \\ Iman Naderi, Ph.D. \\ Fairfield University, Fairfield, CT, USA \\ Samaneh Torkzadeh, Ph.D. \\ Indiana University South Bend, South Bend, IN, USA
}

To link to this article: https://doi.org/10.1080/19368623.2018.1444527

\begin{abstract}
Even though American health care providers have incessantly raised their prices, medical insurers have managed to achieve (greater) profitability covering fewer services for a smaller number of clientele every year. Against this backdrop, there has been a sharp increase in the number of people seeking health care in foreign countries. Using prospect theory, this study finds medical tourism consideration to be driven by domestic medical costs, patient privacy concerns, medical restrictions, and foreign destination desirability. The latter is in turn influenced by tourist attractions and service quality assurance in addition to domestic medical costs. The findings and their implications and limitations are also discussed.
\end{abstract}

Keywords: Medical Tourism; Destination Desirability; Medical Costs; Care Quality; Privacy, Attractions 


\section{Introduction}

Medical tourism refers to the medical care decision where by patients elect to travel across international borders with the intention of receiving some form of medical treatment for the enhancement or restoration of their health (Hudson \& Li, 2012; Lunt et al., 2011). Although the primary motive of such travel is seeking medical care that is not easily accessible or available in the home country, patients have been found to incorporate leisure, fun, and relaxation activities as part of their decision (Heung, Kucukusta, \& Song, 2010). The size of medical tourism industry is currently estimated at $\$ 45-100$ billion, with a projected growth rate of up to $25 \%$ year-over-year for the next 10 years (Medical Tourism Magazine, 2016; Patients Beyond Borders, 2017). Approximately 14 million cross-border patients travel worldwide every year, spending an average of $\$ 3,800-7,000$ per visit on medically-related costs, cross-border and local transport, inpatient stay and accommodations (Medical Tourism Association, 2013; Patients Beyond Borders, 2017). This market is projected to expand globally in the next decade as an estimated that $3-4 \%$ of the world's population will travel internationally for healthcare and health-related treatment (Medical Tourism Magazine, 2016). Within the United States alone, approximately 1,400,000 Americans are expected to travel outside the US for medical care in 2017 (Patients Beyond Borders, 2017) and over $40 \%$ of Americans see medical tourism as a practical future option for themselves (Pafford, 2009).

Medical tourism has been examined by international trade economists as the transfer of medical services across borders (Mattoo \& Rathindran, 2006). Using the income approach, they have documented the sizeable impact of medical tourism on the host countries' economic development (e.g., Lee \& Hung, 2010; Pafford, 2009). Consequently, many countries, especially developing countries in Asia, have been planning legally and practically to take advantage of this expanding market (Heung, Kucukusta, \& Song, 2010). In fact, Ramirez de Arellano (2007) argues 
that investing in the medical industry is a way to improve services, generate foreign exchange, and boost tourism. Despites its prevalence and importance, medical tourism has only recently been the focus of academic studies. Previous research that exists in this domain primarily investigates medical tourism industry from either the supply or demand perspective (e.g., Connell, 2006; Smith \& Forgione, 2007). For instance, Smith and Forgione (2007) proposed a two-stage model indicating the factors that influence a patient's decision to seek medical services in other countries. According to this model, the choice of destination is influenced by country-specific characteristics, such as economic conditions, political climate, and regulatory policies whereas such factors as costs, hospital accreditation, quality of care, and physician training are expected to have an impact on the choice of health-care facilities (Smith \& Forgione, 2007). Further, Österle, Johnson, and Delgado (2013) argued that while cost, access, and care quality influence a patient's decision regarding where to seek care, other factors may simultaneously influence the decision about the care destination, including culture, social factors, and the institutional environment. Similarly, Henson, Guy, and Dotson (2015) found that destination country economic development and safety, destination culture, and travel matters are some the specific factors that influence patients to seek foreign medical care. In another study, Ye, Yuen, Qiu, and Zhang (2008) investigated the motivations and barriers to medical tourism and found that the motivations of medical tourists differ from those of their mass tourism counterparts; the former are more concerned with medical factors than destination attributes.

In a comprehensive review of existing literature in this domain, Heung, Kucukusta, and Song (2010) argued that the existing theoretical models in medical tourism literature do not adequately explain the medical tourism phenomenon and thus there is a clear need for further study of this important tourism sector. They also offered a "tentative" framework for the study of medical tourism and called for addressing the dearth of empirical research on the topic. This research aims 
to answer this call and is focused on the "demand side" of the equation. More precisely, the main objective of this research is to explore motivational factors that lead people to seek medical tourism as a viable option for their health care needs. In doing so, we draw on the prospect theory and empirically model Medical Tourism Consideration (MTC) and choice of destination. The model proposed in this research, which is developed based on a comprehensive review of the literature as well as the findings of two focus group studies, highlights the key factors that potential medical tourists may perceive to be influential in their intentions (or lack thereof) to seek health-care services abroad. Thus, this study provides a better understanding of the consumer side of medical tourism. Considering the implications medical tourism has on the health and wellness of consumers in the home country, this is a topic that deserves the attention of the health care community including medical care providers, insurance companies, the government, as well as other organizations involved directly or indirectly in the decision. Toward that end this study offers practical implications for policy makers and professionals involved (e.g., hospitals and other health-care institutions, travel and tourism agencies). The remainder of the article is structured as follows. First, the existing literature in this domain is reviewed. The hypotheses are then developed and empirically tested, followed by the discussion of findings. Finally, the practical implications of this study, as well as its limitations and directions for further research, are discussed.

\section{Literature Review}

The prominence of MTC is better understood in the broader context of the global health care industry. According to a Deloitte's (2017) report, percentage of global GDP spent on health care is projected to rise slightly from an estimated $10.4 \%$ in 2015 to $10.5 \%$ in 2020 , reaching $\$ 8.7$ trillion. In the United States alone, total health care spending for 2016 reached nearly $\$ 3.4$ trillion, which is partially attributed to rising prices for health care services (Centers for Medicare and Medicaid Services [CMS], 2017; Samli, 2010). CMS also estimated that health care spending will 
account for 19.9 percent of GDP by 2025, up from 17.8 percent in 2015. Medical price growth are also projected to accelerate from an average of 2.4 percent from 2018 to 2019 to an average of 2.7 percent for 2020 to 2025 . At the same time, medical insurers have found ways to increase their profits while covering fewer services for a smaller number of clientele every year (Rosenfeld, 2011). These trends place a dual strain on patients and health care providers. On the one hand, the number of Americans seeking medical treatment in foreign countries has increased sharply even though it is often fraught with uncertainty and risk. On the other hand, the number of foreign patients who travel to the U.S. for medical purposes has been declining (Brown, 2008; Johnson \& Garman, 2010; Rhea, 2008).

MTC occurs because people seek greater value and control when faced with medical decisions (e.g., Wang, 2012). The increasing cost of medical treatments in developed countries, long waiting lists, non-reimbursement of certain medical costs, marinating privacy and confidentiality, growing technological sophistication and improvement in the quality and safety of treatments available overseas, availability of travel intermediaries, simplicity of travel to foreign nations and relative affordability of international air travel, incentives available to global care seekers, employer and insurance company endorsement and possibility of combining the visit with a mini-vacation have all been cited as drivers of MTC (e.g., Connell, 2006; Heung et al., 2010; Jadhav, Yeravdekar, \& Kulkarni, 2014; Maniam, 2015; Menvielle, Menvielle, \& Tournois, 2011; Singh, 2013; Ye et al., 2008).

However, MTC is not without substantial risks such as unsafe practices by foreign professionals and facilities, poor and substandard quality of services, risk of travelling after a surgery, transmission of antibiotic resistant organisms that may be prevalent in foreign countries, discontinuity of medical documentation, minimal legal recourse, and difficulty of after-care coordination once the patient returns home (Center for disease Control, 2013; Crooks et al., 2013). 
Since MTC involves value seeking and decision making under conditions of risk and uncertainty, we develop our conceptual model under the rubric of prospect theory (Kahneman \& Tversky, 1979). Prospect theory views tourists as value-maximizers during the decision-making process, with value rooted in the gains and losses that each alternative entails given the certainty level of each feature under consideration (Kahneman \& Tversky, 1979). Two predictions under the auspice of prospect theory are particularly germane to MTC. First, certainty effect refers to people's tendency to give more weight to features that they consider to be certain relative to features that are merely probable. It follows that tourists tend to be risk-averse when choices involve sure gains and risk-seeking when choices involve sure losses. Second, isolation effect refers to people's tendency to simplify their choice-making by isolating and focusing on features that differ across alternatives. Relying on prospect theory as well as the reviewed literature, we develop a conceptual model and a set of hypotheses as summarized in Figure 1.

\section{-------- Insert Figure 1 about here ---------}

\section{Drivers of MTC}

\section{Domestic Medical Costs}

The major factor that has led to a vast increase in medical tourism is the continually increasing health care expenses such as insurance and medical procedures in developed countries, especially in the U.S. (Abd Mutalib et al., 2017; Brown, 2008; Hall, 1992; Heung et al., 2010; LaRocco \& Pinchera, 2011; Maniam, 2015; Menvielle et al., 2011; Singh 2013; Smith \& Forgione, 2007). In fact, MTC is primarily driven by patients' need to reduce their medical expenses (Johnson \& Garman, 2010; Reddy, York, \& Brannon, 2010). Marlowe and Sullivan (2007) identify cost advantage of foreign medical services as the main precursor of MTC. People who need or desire certain health care services might not afford those services. Even if they can afford the bills, cost differentials often serve as a strong incentive to seek alternative providers. For instance, a 
heart valve replacement surgery approximately costs $\$ 170,000$ in the U.S. whereas the price for the same procedure is around $\$ 28,200$ in Mexico and $\$ 9,500$ in India (Medical Tourism Association, 2016). Similarly, the World Health Organization study reveals that the common procedure of a knee replacement would cost $\$ 48,000$ in the U.S., $\$ 8,500$ in India, $\$ 10,000$ in Thailand, and \$6,375 in Poland (Kelley, 2013). Even patients who are insured may have strong incentives for MTC because receiving health care services is sometimes accompanied by the possibility of significant increases in insurance premium as information about their recent medical conditions makes its way to insurance companies (Brown, 2008). In addition, several medical insurance companies (e.g., Blue Cross Blue Shield, Health Net) now offer medical tourism options as part of their offerings (Keckley \& Underwood, 2009). In summary, despite the risks and uncertainties involved, medical tourism is a viable health option for people under various insurance plans as well as the uninsured and under-insured individuals.

Both isolation effect and certainty effect underscore the importance of cost differential in MTC. Unlike some features that tourists perceive to be common among alternative destinations, healthcare-related monetary costs may substantially differ across these alternatives. For instance, the average cost of a heart bypass procedure is approximately $\$ 7,900$ in India, $\$ 13,900$ in Turkey, and $\$ 27,000$ in Mexico (Medical Tourism Association, 2016). While the literature suggests that relative medical costs may influence a medical tourist's choice of an international medical facility only after selecting the destination country (Heung et al., 2010; Smith \& Forgione, 2007), tourists are also expected to isolate and focus on relative monetary costs when deciding whether to seek medical services abroad at the first place. Moreover, tourists may view monetary costs as a relatively more certain feature of each alternative destination compared to other factors such as service quality (Darby \& Karni, 1973) or legal risks (Mirrer-Sunger, 2017); as such, they are expected to give it more weight. In fact, the Medical Tourism Association's patient surveys 
indicate that nearly $80 \%$ of the demand for medical travel is driven by cost savings and the cost of medical treatment is the most important factor (85\%) in patients' decision to travel abroad for treatment (Medical Tourism Association, 2013). Since monetary costs represent losses (as opposed to gains), prospect theory predicts that tourists will exhibit risk-seeking behavior by choosing the less costly alternative despite the risks emanating from other features under consideration. Therefore, when overseas alternatives are perceived to involve relatively less monetary costs, tourists are expected to prefer such alternatives.

H1: The higher medical costs in home country relative to other countries, the stronger the MTC.

\section{Patient Privacy}

Previous research suggests that cost differential is not the only driver of MTC (Heung et al., 2010). Another risk that can encourage patients to consider medical tourism is the lack of privacy regarding their medical intentions and procedures at home (Horowitz et al., 2007; Jadhav et al., 2014). In this study, privacy is defined as the absence of any disclosure of information about the medical decisions patients make, procedures they receive, and results they experience to the patient's family, social network, health care system, and insurance industry. For instance, patients who seek drug rehabilitation, gender transformation surgery, or plastic surgery often desire that certain individuals, groups, and businesses (i.e., health care and insurance industries) not be made aware of their decisions and actions.

Patients' concern over their health information has been a long standing issue. According to the Health Insurance Portability and Accountability Act (HIPAA) enacted in 1999, patients must consent for the transfer of their medical information between health care providers. However, the 2003 amendments to the HIPAA's privacy rule allow over 600,000 “covered entities" (i.e., health care providers) and their business associates to share patients' medical records without their 
consent and even notice (Herman \& Peel, 2004). Similarly in Europe, a special Eurobarometer on Data Protection showed that most citizens did not feel in control of what happens to their data nowadays (European Commission, 2015) and the new data privacy regulations (effective in 2018) will allow sharing of patients' health and genetic data for healthcare purposes, for public interest in the area of public health, and/or for other specific reasons (European Patients Forum, 2016). Furthermore, the relatively recent digitization of medical information exacerbates patient privacy concerns (Laric \& Pitta, 2009). For these reasons, receiving medical procedures away from home country is often the most convenient, effective, and less risky way to preserve privacy and confidentiality.

The association between medical patient privacy and MTC is supported by both isolation and certainty effects. Patient privacy is an important condition distinguishing between a domestic medical service and a foreign alternative as well as between two foreign alternatives. As such, patients are likely to isolate and focus on this feature when considering various alternatives. Furthermore, receiving medical services domestically is indeed accompanied by significant information sharing among various constituencies, a certain outcome of domestic alternatives that is not necessarily the case with medical tourism. Consequently, patients are expected to place greater weight on privacy. Since threats to privacy represent losses (as opposed to gains), patients will likely engage in risk-seeking behavior by choosing the alternative that offers greatest privacy. Therefore, as foreign alternatives are perceived to involve less privacy concerns, patients tend to prefer such alternatives.

H2: The higher the concern with patient privacy in home country, the stronger the MTC.

\section{Medical Restrictions}

Past research indicates that patients are traveling abroad in search of certain procedures that are not conveniently available in their home countries due to a host of reasons (e.g., long 
waiting periods to receive care; Menvielle et al., 2011; Singh 2013) or procedures that the home government prohibits and prosecutes such as organ transplant and stem cell therapy (Annas, 1985).

In U.S., for example, stringent restrictions exist on the supply of organs for heart and liver transplantation, the number and kind of facilities performing the procedures, and health conditions of the receiving patients (Annas, 1985). Such restrictions have resulted in excessively long waiting lists for receive a lifesaving organ transplant. Currently, there are nearly 120,000 people waiting for lifesaving organ transplants in the U.S. alone and the average number of people who die each year due to excessive wait time is estimated to be between 7,300 and 11,000 - or $20-30$ people every day (statistics slightly vary; American Transplant Foundation, 2017; Donate Life America, 2014; National Kidney Foundation, 2016; Organ Procurement and Transplantation Network, 2017). Similarly in the European Union, a total of over 63,000 patients were officially on organs' waiting lists in 2013. It is also estimated that 4,100 patients died while on these waiting lists in the course of 2013 (European Commission, 2014). MTC for these patients is driven more by the mere availability of services in foreign countries than by the cost disadvantage of domestic providers or privacy concerns. Medical restrictions are intimately linked to MTC according to isolation effect. In fact, availability and legality of specific medical services, when such differences exist, are the ultimate criterion that sets apart domestic and foreign alternatives. Therefore, medical restrictions in home country tend to sway patients towards medical tourism.

H3: The higher the medical restrictions in home country, the stronger the MTC.

\section{Destination Desirability}

Patients who choose to receive medical services outside their home countries often have multiple destination options, with each destination offering a unique combination of attractive features beyond health care (Abd Mutalib et al., 2017). Dann (1977) identifies the attractive features of the destination country as part of the "pull factors" in his travel decision model. 
Moreover, Smith and Forgione (2007) argue that medical tourism is a partial function of the economic conditions, political climate, and regulatory policies of the destination country, followed by the characteristics of the medical facility such as costs of services, physician expertise, quality of care, and accreditation. Finally, Heung et al. (2010) argue that people often stumble over certain destination countries without mindful search. Some people might be considering attractive vacation destinations for the sake of vacation only, but later realize that they could also receive certain medical procedures at a much lower cost in that country. Others might feel forced to choose one of the few available destinations based primarily on their medical needs. In sum, the literature suggests that MTC is also influenced by perceived destination desirability.

H4: The more desirable the destination country, the stronger the MTC.

Drivers of Destination Desirability

\section{Domestic Medical Cost}

As noted, the gap between cost of domestic and foreign care continue to grow leading patients to seek foreign health care services (Mason \& Wright, 2011). The fractional cost of care in medical tourism destinations might not only urge patients to disfavor medical services available in their home countries, but also serve as a decisive factor in the choice of destination. Since there are usually multiple foreign countries that offer the sought-after procedures, patients have to eventually choose one country as their destination. A key consideration for prospective medical tourists who face multiple destination options is the relative cost associated with each option (Heung et al., 2010). For example, relative to their average cost in the U.S., health care services are, on average, 65-90\% less expensive in India, 40-65\% in Mexico, 50-65\% in Turkey, 45-65\% in Costa Rica, and 20-30\% in Brazil (Patients Beyond Borders, 2017). Patients are likely to give more consideration to those countries that offer the intended service at the least practical cost. 
An important factor that in part determines the relative standing of each destination option in terms of cost differential is the coverage provided by patients' own insurance companies. For example, some American insurance companies (e.g., Blue Cross Blue Shield, United Group Program) now allow their clients to seek certain medical procedures at certain medical facilities in Mexico while resting assured that they will be covered for related expenses. This phenomenon appears to be a win-win-win initiative where all of the parties involved benefit from the continued coverage. In terms of isolation effect and certainty effect, the same arguments stated in support of H1 above, apply to the association between cost differential and destination desirability. Therefore, we hypothesize:

H5: The higher medical costs in home country relative to other countries, the more desirable that country as destination.

\section{Tourist Attractions}

As globalization of health care services continues, many countries, especially developing ones, see an opportunity to generate revenues through promoting and offering a host of medical and entertainment services to medical tourists (Awadzi \& Panda, 2006; Crouch \& Ritchie, 1999; Keaney, 2002). This trend has intensified competition among providers and given patients more options and destinations to choose from. For instance, in an effort to increase the contribution of the tourism industry to GDP, China's tourism authorities have prioritized medical tourism, paying particular attention to combining tourist attractions and medical facilities in the same marketing and advertising campaigns (Heung \& Kucukusta, 2013). Another example is Hungary, which attracts patients who try to combine treatment with exploration of the country's renowned attractions (Jónás-Berki, Csapó, Pálfi, \& Aubert, 2015).

Tourist attractions often enable patients to choose one destination over another (MedinaMuñoz \& Medina-Muñoz, 2014). In fact, the availability of affordable medical services in other 
countries serves as a justification for taking a long desired vacation with less feeling of guilt (Dolnicar, Lazarevski, \& Yanamandram, 2013; Horowitz et al., 2007), especially when insurance companies offer coverage in destination countries. The tourist attractions that these patients perceive in regards to each country also help determine destination consideration set. The isolation effect is at play here, as well. Patients tend to see tourist attractions as another source of value exploitable through medical tourism and a distinguishing feature that increases the appeal of medical tourism options relative to domestic options. Thus, we hypothesize:

H6: The more tourist attractions in a country, the more desirable that country as destination.

\section{Service Quality Assurance}

The required or expected quality of medical services is one of the key determinants of destination desirability. In fact, Henson et al. (2015) argued that confidence in medical care quality, which includes hospital or doctor credentials/accreditation as well as their success rate and reputation in treating the condition, is the most significant factor in this context. Similarly, Wongkit and McKercher (2016) found that quality considerations are pre-eminent regardless of the type of treatment sought and Han and Hyun's (2012) study revealed that trust in the medical clinic and its staff is a significant decision factor for patients seeking medical treatments overseas.

Medical services are high in credence properties, which make it difficult, if at all possible, for the patient to ascertain and evaluate service quality even after receiving them. Services high on credence properties are difficult to evaluate due to the level of skills and knowledge required for comprehending the effects and quality of these services (Darby \& Karni, 1973). Tourism, on the other hand, is a service high in experience properties because tourists can best determine the value they receive during or after the tour and through first-hand experience (Nelson, 1970). Therefore, patients in grave need of risky and more complicated medical care (e.g., those seeking an organ transplant or a bypass surgery) may first determine what medical facilities in which countries offer 
the focal services at a competitive cost and quality (e.g., qualifications of the physician, availability of certain medical equipment and technology; Abd Mutalib et al., 2017; Singh, 2013) and only then consider tourism possibilities in those countries. For such patients, the vacation functions will be more marginal (Lunt et al., 2011) compared to quality assurance procedures in provider organizations, which are intended to safeguard the quality of care provided to tourists (Johnston et al., 2010). On the other hand, vacationing preferences could be a significant component of consumer decision-making for patients who seek to receive a low-risk medical procedure (Lunt et al., 2011). Beyond their differences, these two groups share an interest in publicly available and professionally certified assurances of service quality (Horowitz et al., 2007; Hudson \& Li, 2012; Turner, 2007). In fact, Carabello's (2008) study revealed that most American travelers chose a medical facility based on destination interest combined with medical services. In response, promoting medical centers as highly customer-focused service providers that employ clinicians with overseas experience (training, employment, registration) has been a prevalent theme in medical tourism advertising (Lunt et al., 2011; Turner, 2007).

The most convenient assurance used by medical tourists is the certification of medical facilities and personnel by such internationally recognized institutions as the Joint Commission International (JCI), the International Organization for Standardization (ISO), and the Trent Accreditation Scheme (TAS; Heung et al., 2010). However, certification as a source of advantage is gradually waning away from developed countries as an increasing number of private- and staterun medical facilities seek and acquire sufficient certification. For example, in the three-year window between 2008 and 2011, the number of accredited hospitals has grown from 3 to 20 in Mexico, from 12 to 25 in Brazil, from 10 to 17 in India, and from 14 to 24 in Thailand (JCI, 2011). While the expensive costs of health care in the U.S. may drive individuals to seek medical care abroad, service quality and the accreditation of organizations make a strong impact on destination 
decisions. In fact, several organizations such as the American Medical Association strongly recommend that American medical tourists only consider JCI recommended clinics and physicians (Rhea, 2008). Given these observations, service quality assurance in part determines perceived destination desirability.

H7: The more the service assurances in a country, the more desirable that country as destination.

\section{Method}

Instrumentation

Instrument development consisted of three stages. In the first stage, we scanned the extant medical tourism literature (cf., Heung et al., 2010; Horowitz et al., 2010; Marlowe \& Sullivan, 2007; Pafford, 2009) for keywords and phrases that could facilitate the writing of one or more items for any of the seven variables. If available, existing items were adopted to measure the constructs.

In the second stage, two video-taped focus groups were used to discuss and augment the keyword/phrase list and develop multiple items per variable. Since medical tourism is high in experience and credence properties (Darby and Karni, 1973; Steenkamp, 1990), patients who have never been engaged, at least cognitively, with medical tourism are expected to be unaware of the requirements, thought processes, and decision criteria involved in MTC. As such, focus group participants were selected purposively to ensure that they had prior experience with medical tourism or, at least, had considered it in the past. The first focus group was 105 minutes long and consisted of eight staff and faculty members at a comprehensive university in Southwestern United States. Four participants were male, between 29 and 46 years old and the other four were female, between 37 and 53 years old. Participants in the second, 124-minute long focus group were seven non-university professional adults recruited using the authors' social networks. Three participants 
were male, between 38 and 55 years old and the other four were female, between 35 and 53 years old. In both focus groups, caution was taken to include an almost balanced number of middle and upper income levels. Since the thematic variations of the collected data proved to be minor, no additional focus groups were deemed necessary (McQuarrie, 1993). Procedures as well as findings were similar across the focus groups. To cognitively engage participants with the topic, we first asked them to each prepare a list of factors that, in their opinion, could motivate medical tourism. The lists were then shared and the moderator verified that the factors were reasonably associated with one or more of the variables in our model. Next, the moderator kindled a discussion of participants' experiences and attitudes in regards to medical tourism and home and host countries, digging out personal narratives and emotional accounts. Participants reported a variety of prior experiences such as visiting a general physician for common cold, dentistry works, endoscopy, blood transfusion, physiotherapy, and open heart surgery. While a majority of these experiences were positive, a few negative incidents were also reported. After analyzing the video-recordings of the focus groups, we generated 35 items for the seven variables. The focus groups also suggested that before exposing respondents to tourist attractions, service quality assurance, and destination desirability measures, the instrument should ask them to think of a country they would likely consider as a destination. In the third stage, we checked the content validity of the measures by seeking the expert opinion of three colleagues who were familiar with medical tourism literature. In addition to slight modifications made to some of the items, seven items were removed and one new item was added, resulting in the 29 items used in the questionnaire (see Table 1). Each construct had four to five items, except MTC, which included three items. All of the 29 items were measured on a five-point Likert scale, with ' 1 ' and '5' signifying 'strongly disagree' and 'strongly agree'. The sequence of the 29 items was randomized and six of them were reverse-coded. Reverse-coding helps minimize "straight line" answering by respondents and is recommended 
when respondents are familiar with English language, which was the case here (Fowler, 1995). Four additional items captured respondents' demographic information including age, gender, education, and household income.

\section{Insert Table 1 about here}

Sampling

We recruited respondents who could offer dependable perspectives on the survey questions (Iacobucci \& Churchill, 2010). More specifically, patients who had prior thought about, or experience with, medical tourism were desired; we thus chose to survey the sizable group of Winter Texans who visit Texas every year, mostly from Northern states. A majority of Winter Texans are married and have some college education and over \$50K household income (Simpson et al., 2010). Most reside in their own mobile or RV facilities during their stay (130 days, on average), and enjoy the favorable climate, nearby beaches, social activities, and other tourist attractions. More than half of them have Medicare and/or private insurance. Even though recruitment was conducted in one state, the sample represents tourists from around the United States since the area where respondents were recruited is a popular winter migrant destination (see Cruz-Milán et al., 2016).

The researchers intercepted Winter Texans in early February 2010 at various shopping venues. Each interception began with qualifying the potential respondent for the research. We distributed 560 questionnaires, 12 of which were not returned and nine were returned incomplete. A total of 539 surveys were complete and used in the study, comprising an effective response rate of $96 \%$. Male and female respondents comprised $46.7 \%$ and $53.3 \%$ of the sample, respectively. Respondents' age ranged from 38 to 85 years $(M=50.6)$. Roughly $65 \%$ were 45 years of age or older. High school diploma, bachelor's degree, master's degree, and doctorate degree were the highest education for $40.1 \%, 37.1 \%, 16.8 \%$ and $2.3 \%$ of the sample, respectively. 
The remainder $3.6 \%$ had not completed high school. A majority of the respondents $(73.9 \%)$ reported an annual income of less than $\$ 80,000$, and $12.3 \%$ were earning above $\$ 120,000$ annually.

\section{Analyses and Results}

We subjected the data to exploratory factor analysis (EFA) using the principal components method. The scree test (Horn \& Engstrom, 1979) identified a total of seven factors, which collectively extracted $92 \%$ of the total variance. The rotated factor loadings (with varimax rotation) returned a clear structure (see Table 1). Each of the 29 items loaded strongly on the variable it purported to measure. Main loadings for six of the factors were all above .80 , with the loadings of the seventh factor (i.e., MTC) ranging from .73 to .75. All cross loadings were below .43. Given the adequacy of the observed underlying structure and loadings pattern, the 29 items were treated as constituting an a priori model and a confirmatory factor analysis (CFA) was carried out using AMOS 20.0 to confirm the results of the EFA and test the convergent and discriminant validities of the seven constructs. CFA results (see Table 1) confirm the construct validity. Chi-square was significant at .01 level $\left(\chi^{2}=729.78, d f=356\right)$; GFI = .955; comparative-fit index $(\mathrm{CFI})=.952$; incremental fit index $(\mathrm{IFI})=.952$; root mean square error of approximation $(\mathrm{RMSEA})=.069$. Even though RMSEA is moderate, the other indices are above the recommended thresholds, indicating an acceptable fit and providing support for the hypothesized underlying structure.

As shown in Table 1, the standard loadings range from .81 to .96; Cronbach's $\alpha$ for the seven factors ranged from .90 to .96 ; and the average variance extracted in each factor ranges from .63 to .71 . Inter-factor correlations range from .23 to .73 (see Table 2). Since the loadings, Cronbach's $\alpha$, and the average variances extracted are all above recommended thresholds, the factors hold acceptable convergent validity (McDonald \& Ho, 2002). To determine discriminant validity, squared inter-factor correlations were compared against the average variances extracted 
per factor (Fornell \& Larcker, 1981). Since the range of the former statistics (from .05 to .53) falls below that of the latter (from .67 to .71), the factors possess adequate discriminant validity.

\section{Insert Table 2 about here}

The conceptual model was tested using SEM (see Table 3). Although chi-square was significant $\left(\chi^{2}=746.184\right.$, df $\left.=368, p=0.000\right)$, the overall model fit indices were within recommended ranges: $\mathrm{GFI}=.961 ; \mathrm{CFI}=.956 ; \mathrm{IFI}=.957$; and $\mathrm{RMSEA}=.065$ (Browne \& Cudeck, 1992; Hu \& Bentler, 1999; Rigdon, 1996). While RMSEA is only modest, the other indices are well above the recommended threshold, providing support for the a priori model (Bagozzi \& Heatherton, 1994). MTC was significantly $(\alpha=.001)$ associated with its four hypothesized antecedents including domestic medical costs $(\beta=.381 ; t=6.817)$, patient privacy $(\beta=.182 ; t=$ 2.862), medical restrictions $(\beta=.263 ; t=3.765)$, and destination desirability $(\beta=.239 ; t=4.94)$. $\mathrm{H}_{1}$ through $\mathrm{H}_{4}$ are thus supported. In addition, destination desirability was significantly $(\alpha=.001)$ associated with its three hypothesized drivers including domestic medical $\operatorname{costs}(\beta=.321 ; t=$ $6.129)$, tourist attractions $(\beta=.258 ; t=4.567)$, and service quality assurance $(\beta=.253 ; t=3.954)$. Hence, $\mathrm{H}_{5}$ through $\mathrm{H}_{7}$ are also supported.

Insert Table 3 about here

\section{General Discussion}

The results of the study offer extensive support for all hypotheses as well the application of the isolation effect and certainty effect components of the prospect theory. Based on our analysis the most important driver of MTC is cost differential. In the U.S., health care costs have grown at a faster rate than inflation rates. At the household level, health care costs rose to an average of $\$ 19,393$ in 2011 , a $7.3 \%$ (\$1,319) increase over the year before (Kavilanz, 2011). With a growth rate twice the inflation, health care is becoming increasingly burdensome for insured middle class Americans as their income has been stagnating. The problem is more acute for uninsured and 
underinsured people. Further, as proposed in the study, the result supports the prospect theory. The health care costs are perceived as losses by the consumers (as opposed to gains) there by propelling them toward risk seeking behavior whereby they seek out the less costly alternative at the same time ignoring the other risks involved. Our study offers further support for the crucial role of medical costs. In addition to domestic medical costs, as hypothesized, patient privacy concern can sway people toward medical tourism (Horowitz et al., 2007). Although the enactment of the HIPAA in 1999 promised enhanced patient privacy through prohibiting health care providers from transferring patient information without patient consent (Benjamin, 2002), amendments to the HIPAA in 2003 abolished that promise by allowing almost all providers and their business associates to share patients' medical records without their consent and even notice (Herman \& Peel, 2004). This was exacerbated with the advent of medical records digitization (Laric \& Pitta, 2009). The heightened focus on privacy issues would force them to isolate and focus on the privacy aspect more closely considering the loss of privacy as a potential loss and thus engaging in risk seeking behavior as proposed by prospect theory. As a result, Americans are increasingly concerned with rights to their health records and many pursue medical procedures in foreign countries to proactively maintain privacy ignoring the other risks associated with the decision (isolation effect). Our study also shows that medical restrictions are directly associated with MTC. People travel aboard to seek health care normally for expensive procedures such as cardiac and orthopedic surgeries and organ transplantation (Ryan, 2011). Of such high profile procedures, some are difficult to get domestically for Americans. Coupled with resource scarcity, the stringent regulations that hinder timely and effective treatments place Americans on waiting lists, many of whom die due to excessive wait time (e.g., American Transplant Foundation, 2017; Organ Procurement and Transplantation Network, 2017). Therefore, medical tourism may also be driven 
by domestic medical restrictions as opposed to cost comparisons or privacy issues as per the isolation effect associated with the prospect theory.

As signified by the term itself, medical tourists desire enjoyable experiences in addition to health care services (Carruth \& Carruth, 2010). Therefore, they carefully select the destination country to combine the pursuit of medical treatment with the adventures of touring a different place in a cost-effective manner. In other cases, patients may know of a specific health care provider in a certain country and proceed to explore tourist attractions and activities available therein. At any rate, the desirability of destination country is often assessed in the process of medical tourism decision-making. Our study underscores the importance of destination desirability for MTC.

Traveling abroad in search of the best treatment possible for a particular illness used to be a privilege of wealthy patients (Burkett, 2007). However, rising domestic medical costs and explosion of information available to patients have rendered foreign alternatives economically more justified and professionally more trustworthy for middle class citizens of developed countries, who now consider medical tourism as a viable option (Ryan, 2011). For these patients, cost differential between domestic and foreign providers for a given medical procedure is still the decisive factor (Levary, 2011). Our study supports that domestic medical costs is the most critical indicator of perceived destination desirability.

Destination desirability is also dependent upon the number and attractiveness of tourist sites and activities available in each country. Thanks to the globalization of medical services, developing countries capitalize on their comparative cost advantages to promote and offer a host of medical services to the citizens of other nations, especially the economically advanced ones (Awadzi \& Panda, 2006; Keaney, 2002). As a result, prospective medical tourists have more 
domestic and foreign alternatives to choose from. So, they also consider tourist attractions including the culture, tradition, lifestyle, and places of interest of each destination.

Lastly, destination desirability is also influenced by service quality assurance, also referred to as accreditation, reputation of medical providers, or even quality of medical care in the literature (Heung et al., 2010; Smith \& Forgione, 2007). Despite its cost disadvantage, American health care system enjoys some of the highest medical standards among the industrial nations (Burkett, 2007). Since quality and safety have always been a prime concern when it comes to medical tourism (Carruth \& Carruth, 2010), negative stereotypes about medical conditions in certain developing countries continue to influence the decisions of many medical tourists (Ryan, 2011). Some foreign hospitals and facilities work hard to overcome this enigma in an effort to attract Western medical tourists. In fact, some Southeast Asian countries such as Singapore and India now utilize worldclass facilities and professionals (Gan \& Frederick, 2011; Mudur, 2004).

\section{Implications}

The results of the study offer important theoretical as well as practical implications. On the theoretical front, this study offers a theoretical model for health care decision making in the context of medical tourism. Further, it applies prospect theory to a new but fast growing area of consumer health care decision making. On the practical front, the study offers several insights for several constituents such as health care providers, policy makers, insurance companies as well as the insurance plan sponsors (e.g., companies). For many patients who are desperate but unable to receive certain medical services at home, medical tourism often proves to be a boon. On the flip side, this may also lead to the patients being taken advantage of by rouge facilities or doctors abroad. In order to ensure public health and safety, government agencies may tie up with or at least list the high quality hospitals in popular medical tourism destinations. Further, in the case of non- 
urgent medical procedures, medical outsourcing will also relieve some of the pressure on the U.S. medical care system.

While there are a few existing institutions establishing and certifying such assurances, there are numerous new business opportunities for entrepreneurs, insurance companies, and/or medical providers. Specifically, since patients are increasingly interested in medical tourism while desiring, or even demanding, service quality assurances, potentially profitable opportunities exist in the form of new service or business ideas such as formal agencies bringing the foreign hospitals and patients together, appraisal services that rate the quality of care and care providers across different facilities and destinations, travel and tourism intermediaries specialized in medical tourism, (e.g., travel agents and airlines), and monitoring agencies alleviating patients' post-service concerns.

The finding that patients consider medical tourism in part due to the allure of the destinations, which in turn influenced by the scope and quality of their tourist attractions, is of interest not only to medical service providers, but also to traditional destination marketers. As international destinations continue to grow in number and quality, they face more intense competition over tourists' leisure and tourism budgets. Traditional destination marketers can profit from researching the possibilities of targeting tourists who would be open to the idea of augmenting their vacation plans to take advantage of medical, surgical, or dental services available in the advertised destinations. They can alternatively target patients who consider medical tourism, but know very little about the possibility of mixing business with fun.

Our study underscores the importance of value propositions such as cost differential and service quality assurance that offer important guidelines for medical service providers. Prospect theory suggests that medical providers should shift their focus from features and benefits that tourists perceive to be merely probable to those that tourists identify as significantly more certain. 
Similar strategies can also be formulated by policy makers to reinvigorate the ailing U.S. health care industry as well.

\section{Limitations and Future Research Directions}

The model and findings of this study should be corroborated by future research. First, we studied medical tourism from the demand point of view. It should be investigated on the supply side of the equation, as well (Heung et al., 2010). For instance, a developing country's success in attracting patients from around the world depends in part on how strategically that country proceeds (Crouch \& Ritchie, 1999). Second, although the constructs included in our conceptual model along with their measures are supported by a literature review and focus groups, they should be improved upon in future research. Smith and Forgione (2007) consider economic conditions, political systems, and regulations as other determinants of destination desirability; and Levary (2011) links the choice of destination to tourists familiarity with the foreign language involved as well as distance from home. In addition to these factors, reputation of medical professionals in destination countries, referrals by domestic professionals, and patient word of mouth might also be relevant to the study of MTC even though these have not been previously considered. Third, while prospect theory, as used in this study, is based on the assumption that consumers are rational decision-makers who make choices that will maximize benefits for themselves and minimize any cost, we acknowledge that consumers' cognitive biases often prevent them from making rational decisions, despite their best efforts. Future research could investigate MTC using other behavioral theoretical lenses to address the emotional or subjective aspects of decision making in this context. Last, Winter Texans, albeit representing a cross-section of the country, fall short of representing broader populations of interest. In addition, use of a non-probability sample may limit the reliability of the findings. Future research can extend our study and verify the generalizability of the findings by utilizing more representative samples across the country. We invite researchers to 
further push the boundaries of our knowledge about medical tourism by taking these and other research directions at both micro and macro spheres. 


\section{References}

Abd Mutalib, N. S., Soh, Y. C., Wong, T. W., Yee, S. M., Yang, Q., Murugiah, M. K., \& Ming, L. C. (2017). Online narratives about medical tourism in Malaysia and Thailand: A qualitative content analysis. Journal of Travel \& Tourism Marketing, 34(6), 821-832.

American Transplant Foundation (2017). Facts: Did you know?. Retrieved from https://www.americantransplantfoundation.org/about-transplant/facts-and-myths/ (accessed 09/18/2017)

Annas, G. (1985). Regulating the introduction of heart and liver transplantation. American Journal of Public Health, 75(1), 93-95.

Awadzi, W., \& Panda, D. (2006). Medical tourism: globalization and the marketing of medical services. Consortium Journal of Hospitality \& Tourism, 11(1), 75-81.

Bagozzi, R., \& Heatherton, T. (1994). A general approach to representing multifaceted personality constructs: Application to state self-esteem. Structural Equation Modeling: A Multidisciplinary Journal, 1(1), 35-67.

Benjamin, G. (2002). Patient privacy: a policy shift. (Health Policy Update). Physician Executive, 28(4), 62-65.

Brown, S. (2008). Datapage. Medical tourism: nations vie for health dollars. Hospitals \& Health Networks/AHA, 82(12), 49.

Browne, M. W., \& Cudeck, R. (1992). Alternative ways of assessing model fit. Sociological Methods \& Research, 21(2), 230-258.

Burkett, L. (2007). Medical tourism: concerns, benefits, and the American legal perspective. The Journal of Legal Medicine, 28(2), 223-245.

Carabello, L. (2008). A medical tourism primer for US physicians. The Journal of Medical Practice Management, 23(5), 291-294.

Carruth, P., \& Carruth, A. (2010). The financial and cost accounting implications of medical tourism. The International Business \& Economics Research Journal, 9(8), 135-140.

Center for Disease Control. (2016). Medical tourism: Getting medical care in another country. Retrieved from http://www.cdc.gov/Features/MedicalTourism/ (accessed 06/15/2016)

Centers for Medicare and Medicaid Services. (2011). National health care expenditures data: US Department of health and human services. Retrieved from https://www.cms.gov (accessed 06/15/2016)

Centers for Medicare and Medicaid Services. (2017). 2016-2025 projections of national health expenditures data released. Retrieved from https://www.cms.gov/Newsroom/MediaReleaseDatabase/Press-releases/2017-Pressreleases-items/2017-02-15-2.html (accessed 10/11/2017) 
Connell, J. (2006). Medical tourism: Sea, sun, sand and . . surgery. Tourism Management, 27(6), 1093-1100.

Crooks, V., Turner, L., Cohen, I., Bristeir, J., Snyder, J., Casey, V., \& Whitmore, R. (2013). Ethical and legal implications of the risks of medical tourism for patients: A qualitative study of Canadian health and safety representatives' perspectives. BMJ Open, 3(2).

Crouch, G., \& Ritchie, J. (1999). Tourism, competitiveness, and societal prosperity. Journal of Business Research, 44(3), 137-152.

Cruz-Milán, O., Simpson, J. J., Simpson, P. M., \& Choi, W. (2016). Reassurance or reason for concern: security forces as a crisis management strategy. Tourism Management, 56, 114125.

Dann, G. (1977). Anomie, ego-enhancement and tourism. Annals of Tourism Research, 4(4), 184-194.

Darby, M., \& Karni, E. (1973). Free competition and the optimal amount of fraud. The Journal of Law \& Economics, 16(1), 67-88.

Deloitte (2017). 2017 global health care sector outlook. Retrieved from https://www2.deloitte.com/content/dam/Deloitte/global/Documents/Life-SciencesHealth-Care/gx-lshc-2017-health-care-outlook-infographic.pdf (accessed 10/11/2017)

Dolnicar, S., Lazarevski, K., \& Yanamandram, V. (2013). Quality of life and tourism: A conceptual framework and novel segmentation base. Journal of Business Research, 66(6), 724-729.

Donate Life America (2014). Deaths equivalent to 22 jumbo jets crashing every year due to organ donor shortage - Press release. Retrieved from https://www.donatelife.net/news/deaths-equivalent-to-22-jumbo-jets-crashing-everyyear-due-to-organ-donor-shortage-press-release/ (accessed 09/18/2017).

European Commission (2014). Journalist workshop on organ donation and transplantation: Recent facts \& figures. Retrieved from https://ec.europa.eu/health//sites/health/files/blood_tissues_organs/docs/ev_20141126_fa ctsfigures_en.pdf (accessed 10/13/2017)

European Commission (2015). Data protection report. Retrieved from http://ec.europa.eu/commfrontoffice/publicopinion/archives/ebs/ebs_431_en.pdf (accessed 10/13/2017)

European Patients Forum (2016). The new EU regulation on the protection of personal data: What does it mean for patients?. Retrieved from http://www.eupatient.eu/globalassets/policy/data-protection/data-protection-guide-for-patientsorganisations.pdf (accessed 10/13/2017)

Forgione, D., \& Smith, P. (2006). Medical tourism and its impact on the U.S. health care system. Journal of Health Care Finance, 34(1), 27-35. 
Fornell, C., \& Larcker, D. (1981). Structural equation models with unobservable variables and measurement error: Algebra and statistics. Journal of Marketing Research, 18(3), 382388.

Fowler, F. J. (1995). Improving Survey Questions: Design and Evaluation, Applied Social Research Methods Volume 38 of Applied Social Research. Sage: Thousand Oaks, CA.

Gan, L., \& Frederick, J. (2011). Medical tourism in Singapore: A structure-conduct-performance analysis. Journal of Asia-Pacific Business, 12(2), 141-170.

Hall, C. M. (1992). Adventure, sport and health tourism. In B. Weiler and C. M. Hall (Eds.), Special Interest Tourism (pp. 141-158). London: Belhaven.

Han, H., \& Hyun, S. S. (2012). A cross-cultural study of perceptions of medical tourism among Chinese, Japanese and Korean tourists in Korea. Tourism Management, 33(1), 80-88.

Henson, J. N., Guy, B. S., \& Dotson, M. J. (2015). Should I stay or should I go? Motivators, decision factors, and information sources influencing those predisposed to medical tourism. International Journal of Healthcare Management, 8(1), 4-14.

Herman, B., \& Peel, D. (2004). HIPAA's real effect: the end of medical privacy; a new dilemma for physician executives. Physician Executive, 30(1), 34-38.

Heung, V., \& Kucukusta, D. (2013). Wellness tourism in China: Resources, development and marketing. International Journal of Tourism Research, 15(4), 346-359.

Heung, V., Kucukusta, D., \& Song, H. (2010). A conceptual model of medical tourism: Implications for future research. Journal of Travel \& Tourism Marketing, 27(3), 236-251.

Horn, J., \& Engstrom, R. (1979). Cattell's scree test in relation to Bartlett's chi-square test and other observations on the number of factors problem. Multivariate Behavioral Research, 14(3), 283-300.

Horowitz, M. D., Rosensweig, J. A., \& Jones, C. A. (2007). Medical tourism: Globalization of the healthcare marketplace. Medscape General Medicine, 9(4), 33.

Hu, L., \& Bentler, P. (1999). Cutoff criteria for fit indexes in covariance structure analysis: Conventional criteria versus new alternatives. Structural Equation Modeling: A Multidisciplinary Journal, 6(1), 1-55.

Hudson, S., \& Li, X. (2012). Domestic medical tourism: A neglected dimension of medical tourism. Journal of Hospitality Marketing \& Management, 21(3), 227-246.

Jadhav, S., Yeravdekar, R., \& Kulkarni, M. (2014). Cross-border healthcare access in south Asian countries: Learnings for sustainable healthcare tourism in India. Procedia - Social and Behavioral Sciences, 157, 109-117. 
JCI Accredited Organizations. (2011). Joint Commission International. Retrieved from http://www.jointcommissioninternational.org/about-jci/jci-accredited-organizations/ (accessed 06/15/2016)

Johnson, T., \& Garman, A. (2010). Impact of medical travel on imports and exports of medical services. Health Policy, 98(2), 171-177.

Johnston, R., Crooks, V.A., Snyder, J., \& Kingsbury, P. (2010). What is known about the effects of medical tourism in destination and departure countries? A scoping review. International Journal for Equity in Health, 3(1), 9-24.

Jónás-Berki, M., Csapó, J., Pálfi, A., \& Aubert, A. (2015). A market and spatial perspective of health tourism destinations: The Hungarian experience. International Journal of Tourism Research, 17(6), 602-612.

Kanheman, D. \& Tversky, A. (1979). Prospect Theory: An Analysis of Decision under Risk. Econometrica, 47(2), 263-291.

Kavilanz, P. (2011). Your family's health care costs: \$19,393. Retrieved from http://money.cnn.com/2011/05/11/news/ economy/healthcare_costs_family/index.htm (accessed 06/15/2016)

Keaney, M. (2002). Unhealthy accumulation: The globalization of health care privatization. Review of Social Economy, 60(3), 331-357.

Keckley, P., \& Underwood, H. (2008). Medical tourism: update and implications. Washington, DC: Deloitte Centre for Health Solutions.

Kelley, Edward (2013), "Medical Tourism," World Health Organization, available at http://www.who.int/global_health_histories/seminars/kelley_presentation_medical_touris m.pdf, accessed on 01/26/2018.

Laric, M., \& Pitta, D. (2009). Preserving patient privacy in the quest for health care economies. Journal of Consumer Marketing, 26(7), 477-486.

LaRocco, S., \& Pinchera, B. (2011). The emerging trend of medical tourism. Nursing Management, 42(6), 24-30.

Lee, C., \& Hung, W. (2010). Tourism, health and income in Singapore. International Journal of Tourism Research, 12(4), 355-359.

Levary, R. (2011). Multiple-criteria approach to ranking medical tourism destinations. Thunderbird International Business Review, 53(4), 529-537.

Lunt, N., Smith, R., Exworthy, M., Green, S., Horsfall, D., \& Mannion, R. (2011). Medical Tourism: Treatments, Markets and Health System Implications: A scoping review. Paris: OECD. DOI: http://www.oecd.org/dataoecd/51/11/48723982.pdf 
Maniam, G. (2015). Medical tourism as the result of rising American healthcare costs in the context of healthcare globalization. Journal of Business \& Behavioral Sciences, 27(2), $112-122$.

Marlowe, J., \& Sullivan, P. (2007). Medical tourism: The ultimate outsourcing. Human Resource Planning, 30(2), 8-10.

Mason, A., \& Wright, K. (2011). Framing medical tourism: An examination of appeal, risk, convalescence, accreditation, and interactivity in medical tourism web sites. Journal of Health Communication, 16(2), 163-177.

Mattoo, A., \& Rathindran, R. (2006). How health insurance inhibits trade in health care. Health Affairs, 25(2), 358-368.

McDonald, R. P., \& Ho, M. R. (2002). Principles and practice in reporting structural equation analyses. Psychological Methods, 7(1), 64-81.

McQuarrie, E. (1993). Customer visits. Newbury Park, CA: Sage.

Medical Tourism Association (2013). 2013 MTA medical tourism survey report. Retrieved from http://medicaltourism.com/Forms/facts-statistics.aspx (accessed 10/02/2017)

Medical Tourism Association (2016). Compare prices. Retrieved from http://medicaltourism.com/Forms/price-comparison.aspx (accessed 10/02/2017).

Medical Tourism Magazine (2016). Medical tourism industry valued at $\$ 100 B$; poised for 25\% year-over-year growth by 2025. Retrieved from http://www.medicaltourismmag.com/medical-tourism-industry-valued-at-439b-poisedfor-25-year-over-year-growth-by-2025/ (accessed 10/10/2017)

Medina-Muñoz, D., \& Medina-Muñoz, R. (2014). The attractiveness of wellness destinations: an importance-performance-satisfaction approach. International Journal of Tourism Research, 16(6), 521-533.

Menvielle, L., Menvielle, W., \& Tournois, N. (2011). Medical tourism: A decision model in a service context. Tourism, 59(1), 47-61.

Mirrer-Singer, P. (2007). Medical malpractice overseas: The legal uncertainty surrounding medical tourism. Law and Contemporary Problems, 70(2), 211-232.

Mudur, G. (2004). Hospitals in India woo foreign patients. BMJ, 328, 1338.

National Kidney Foundation (2016). Organ donation and transplantation statistics. Retrieved from https://www.kidney.org/news/newsroom/factsheets/Organ-Donation-andTransplantation-Stats (accessed 09/18/2017)

Nelson, P. (1970). Information and consumer behavior. Journal of Political Economy, 78(2), 311-329. 
Organ Procurement and Transplantation Network (2017). Organ donation and transplantation can save lives. Retrieved from https://optn.transplant.hrsa.gov/ (accessed 09/18/2017)

Österle, A., Johnson, T., \& Delgado, J. (2013). A unifying framework of the demand for transnational medical travel. International Journal of Health Services, 43(3), 415-436.

Pafford, B. (2009). The third wave--medical tourism in the 21st century. Southern Medical Journal, 102(8), 810-813.

Patients Beyond Borders. (2017). Medical tourism - Statistics and facts. Retrieved from http://www.patients beyondborders.com/medical-tourism-statistics-facts (accessed 09/18/2017)

Reddy, S., York, V., \& Brannon, L. (2010). Travel for treatment: students' perspective on medical tourism. International Journal of Tourism Research, 12(5), 510-522.

Rhea, S. (2008). Medical migration. Modern Healthcare, 38(18), 6-7.

Rosenfeld, D. (2011). Health insurers make more, cover fewer people: The Lund report. Retrieved from http://www. thelundreport.org/resource/health_insurers make more _cover_fewer_people (accessed 06/15/2016)

Ryan, K. (2010). Medical tourism: Is now the time to offer this benefit? Benefits Magazine, 48(7), 20-25.

Samli, A. (2010). The medical services paradox in the US market system: The desperate need for improvement. Journal of Macromarketing, 30(4), 398-401.

Simpson, P., Ghaddar, S., \& Sheng, X. (2010). Winter Texan report. Valley Markets \& Tourism Research Center, University of Texas-Pan American.

Singh, N. (2013). Exploring the factors influencing the travel motivations of US medical tourists. Current Issues in Tourism, 16(5), 436-454.

Smith, P., \& Forgione, D. (2007). Global outsourcing of healthcare: a medical tourism decision model. Journal of Information Technology Case and Application Research, 9(3), 19-30.

Steenkamp, J. B. E. (1990). Conceptual model of the quality perception process. Journal of Business research, 21(4), 309-333.

Tucki, A., \& Cleave, P. (2014). Medical tourism: New growing industry on a concealed market. European Journal of Medical Technologies, 4(5), 1-7.

Turner, L. (2007). First world health care at third world prices: Globalization, bioethics and medical tourism. BioSocieties, 2(3), 303-325.

Wang, H. (2012). Value as a medical tourism driver. Managing Service Quality, 22(5), 465-491. 
World Health Organization. (2010). Health systems financing: The path to universal coverage. The World Health Report. Retrieved from http://apps.who.int/iris/bitstream/10665/44371/1/9789241564021_eng.pdf

Wongkit, M., \& McKercher, B. (2016). Desired attributes of medical treatment and medical service providers: A case study of medical tourism in Thailand. Journal of Travel \& Tourism Marketing, 33(1), 14-27.

Ye, B. H., Yuen, P. P., Qiu, H. Z., \& Zhang, V. H. (2008). Motivation of medical tourists: An exploratory case study of Hong Kong medical tourists. Paper presented at the Asia Pacific Tourism Association (APTA) Annual Conference, Bangkok, Thailand. 
Table 1 - EFA and CFA Results (Measurement Model)

\begin{tabular}{|c|c|c|}
\hline & $\begin{array}{l}\text { EFA }^{\mathrm{a}} \\
\text { Loading }\end{array}$ & $\begin{array}{l}\text { CFA }^{b} \\
\text { Path }\end{array}$ \\
\hline \multicolumn{3}{|l|}{ Medical Restrictions $\alpha=.96^{\mathrm{c}} ; \mathrm{AVE}=.66^{\mathrm{d}}$} \\
\hline There are some medical restrictions in U.S. & .842 & .847 \\
\hline Some medical services are not available in U.S. & .869 & .859 \\
\hline Certain treatments available overseas are not provided in U.S. & .853 & .854 \\
\hline Some people have to seek certain medical services overseas. & .872 & .880 \\
\hline \multicolumn{3}{|l|}{ Patient Privacy $\alpha=.93 ; \mathrm{AVE}=.64$} \\
\hline $\begin{array}{l}\text { When the medical service provider is American, patient information is more accessible to } \\
\text { American insurance companies. }\end{array}$ & .870 & .895 \\
\hline Receiving medical services overseas enhances patient privacy in U.S. & .879 & .912 \\
\hline $\begin{array}{l}\text { No matter in what country one receives medical services, American insurance companies } \\
\text { have equal access to patient information. }{ }^{\text {e }}\end{array}$ & .896 & .916 \\
\hline One way to enhance patient privacy is to use foreign providers. & .900 & .932 \\
\hline \multicolumn{3}{|l|}{ Domestic Medical Costs $\alpha=.95 ; \mathrm{AVE}=.64$} \\
\hline Medical services are less expensive in U.S. ${ }^{e}$ & .858 & .823 \\
\hline American medical service providers charge an arm and a leg. & .878 & .862 \\
\hline Medical services are more affordable in U.S. ${ }^{\mathrm{e}}$ & .811 & .813 \\
\hline It is more costly to receive medical services in U.S. & .899 & .966 \\
\hline Medical services are overpriced in U.S. & .894 & .959 \\
\hline \multicolumn{3}{|l|}{ Tourist Attractions $\alpha=.93 ; \mathrm{AVE}=.67$} \\
\hline There are many tourist attractions in that country. & .896 & .874 \\
\hline That country is a pleasant place for any tourist. & .907 & .940 \\
\hline There are amusing things to do in that country. & .870 & .810 \\
\hline That country is not attractive to tourists. ${ }^{\mathrm{e}}$ & .896 & .913 \\
\hline I will visit that country as a medical tourist. & .921 & .949 \\
\hline \multicolumn{3}{|l|}{ Service Quality Assurance $\alpha=.94 ; \mathrm{AVE}=.69$} \\
\hline The acceptable quality of medical services in that country is known to me. & .888 & .894 \\
\hline The medical services in that country are certified. & .900 & .899 \\
\hline I am assured I'll receive services at an acceptable level of quality in that country. & .896 & .888 \\
\hline I have not come across any quality assurance about medical services in that country. ${ }^{\mathrm{e}}$ & .882 & .891 \\
\hline \multicolumn{3}{|l|}{ Destination Desirability $\alpha=.90 ; \mathrm{AVE}=.71$} \\
\hline That country is a desirable place for me as a medical tourist. & .890 & .930 \\
\hline That country is a suitable place to receive my intended services. & .903 & .948 \\
\hline That country is not appropriate for me as a medical tourist. ${ }^{\mathrm{e}}$ & .899 & .940 \\
\hline I would recommend that country to anyone with similar needs. & .884 & .912 \\
\hline \multicolumn{3}{|l|}{ MTC (Medical Tourism Consideration) $\alpha=.93 ; \mathrm{AVE}=.63$} \\
\hline $\begin{array}{l}\text { I will consider traveling to another country to receive medical services if I have major } \\
\text { medical needs. }\end{array}$ & .730 & .848 \\
\hline Medical tourism might be a practical option for me in future. & .747 & .916 \\
\hline Certain treatments might motivate me to seek medical services in a foreign country. & .736 & .911 \\
\hline
\end{tabular}

a Principal Components Analysis, varimax rotation

b CFA $1^{\text {st }}$-order measurement model standardized regression weights, all path coefficients significant at $p<.001$.

c Cronbach's Alpha

d Average Variance Extracted in CFA

e Reverse-coded items 
Table 2 - Correlation Matrix and Descriptive Statistics

\begin{tabular}{llllllllll}
\hline & $\mathrm{M}$ & $\mathrm{SD}$ & 1 & 2 & 3 & 4 & 5 & 6 & 7 \\
\hline 1. Medical restrictions & 2.80 & .98 & 1.00 & & & & & & \\
2. Patient privacy & 2.76 & 1.12 & .426 & 1.00 & & & & & \\
3. Domestic medical costs & 3.40 & 1.18 & .401 & .351 & 1.00 & & & & \\
4. Tourist attractions & 2.73 & 1.22 & .360 & .342 & .374 & 1.00 & & & \\
5. Service quality assurance & 2.35 & 1.08 & .382 & .380 & .405 & .345 & 1.00 & & \\
6. Destination desirability & 3.48 & 1.15 & .501 & .514 & .646 & .478 & .314 & 1.00 & \\
7. Medical tourism consideration & 3.50 & 1.34 & .512 & .435 & .631 & .228 & .448 & .730 & 1.00 \\
\hline
\end{tabular}


Table 3 - Hypothesis Testing with SEM (Structural Model)

\begin{tabular}{lccll}
\hline Path & Standardized $\beta$ & $S E$ & $P$ & Hypothesis \\
\hline Domestic medical costs $\rightarrow$ MTC ${ }^{\text {a }}$ & .381 & .056 & $<.001$ & H1 supported \\
Patient Privacy $\rightarrow$ MTC & .182 & .064 & $=.004$ & H2 supported \\
Medical restrictions $\rightarrow$ MTC & .263 & .070 & $<.001$ & H3 supported \\
Destination desirability $\rightarrow$ MTC & .239 & .048 & $<.001$ & H4 supported \\
Domestic medical costs $\rightarrow$ Destination desirability & .321 & .052 & $<.001$ & H5 supported \\
Tourist attractions $\rightarrow$ Destination desirability & .258 & .057 & $<.001$ & H6 supported \\
Service quality assurance $\rightarrow$ Destination desirability & .253 & .064 & $<.000$ & H7 supported \\
Model Fit: $\chi^{2}=746.184(d f=368), p=0.000$ & & & & \\
GFI $=.961 ; C F I=.956 ;$ IFI $=.957 ;$ RMSEA $=.065$ & & & & \\
\hline
\end{tabular}

a Medical Tourism Consideration 
Figure 1 - The Conceptual Model

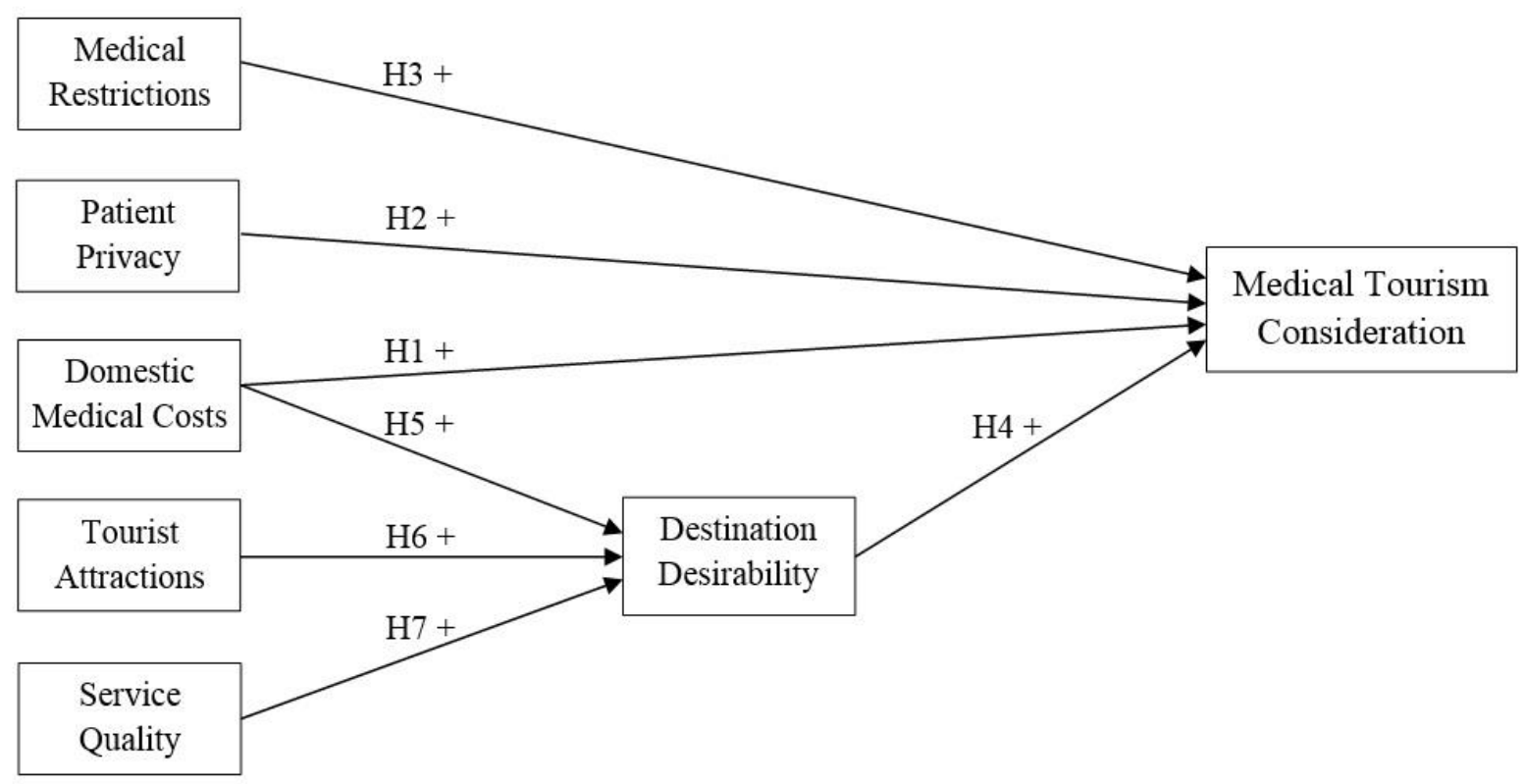

